U.S. Department of Commerce, Bureau of Standards

RESEARCH PAPER RP658

Part of Bureau of Standards Journal of Research, vol. 12, March 1934

\title{
REPRODUCIBILITY OF THE ICE POINT
}

\author{
By James L. Thomas
}

ABSTRACT

In order to test the ice point as a suitable temperature at which to measure pure-metal resistance standards, an investigation has been made of its reproducibility. The results obtained show that the ice point may be readily reproduced to a few ten thousandths of a degree centigrade. This result was arrived at by intercomparing different ice baths, and by comparing the ice point with the triple point of water.

\section{CONTENTS}

Introduction

1. Introduction

II. Resistance measurements. 323

III. Triple-point measurements. 324

IV. Summary

\section{INTRODUCTION}

The temperature of an ice bath is known to depend upon a number of factors, that is to say, the ice point depends upon the kinds and amounts of impurities, both solid and gaseous, present in the ice bath, as well as upon the barometric pressure.

It is the purpose of this paper to present some evidence that the temperature of ice baths, even when prepared from commercial ice, is reproducible to a few ten thousandths of a degree centigrade. This conclusion was arrived at not only by comparing the temperature of ice baths with one another, but also by comparing their temperature with that of the triple point of water.

\section{RESISTANCE MEASUREMENTS}

In the paper ${ }^{1}$ immediately preceding this one is a description of a number of $1-0 h m$ resistance standards made of pure metals, which are measured at the temperature of melting ice. Before they were constructed a preliminary investigation was made of the reproducibility of the temperature of the ice point. For this purpose a $10-\mathrm{ohm}$ copper resistance coil was mounted in a double-walled container and arranged so that its resistance while immersed in an ice bath could be measured with a Thomson double bridge. The resistance of this coil was measured in 6 separate ice baths, the measurements extending over a period of 5 days. During this short period of time the resist- 
ance of the copper coil as well as that of the manganin standard with which it was compared probably remained constant. Any variation in the measured resistance was due either to uncertainties of the electrical measurements or to differences in the temperature of the various ice baths. The resistance comparisons were made to 1 part in 1 million and the observed change in resistance was also 1 part in 1 million, corresponding to a temperature change of $0.00025^{\circ} \mathrm{C}$ at most.

The pure-metal resistance standards described in the paper referred to above, together with the bridge, constitute accurate resistance thermometers. The resistances of two of these standards no. 1 (copper), and no. 5 (platinum), observed and recorded to 1 part in 1 million over a period of about 5 months, from November 1932 to May 1933, may be used for purposes of illustration. Allowing for a slow drift in the resistance of the copper standard, assumed to occur at a uniform rate, these observations may be interpreted as indicating the differences in the temperatures of the ice baths used during that period. When so interpreted, the data indicate that the average difference from the mean was $0.00015^{\circ} \mathrm{C}$ for observations with standard no. 1 , and $0.0001^{\circ} \mathrm{C}$ for observations with standard no. 2 , while the maximum deviation from the mean was $0.0005^{\circ} \mathrm{C}$, observed with the copper standard. The entire range in temperature indicated by the platinum coil could be attributed to uncertainties in the electrical measurements, as could part of that indicated by the copper coil. That it is possible to prepare duplicate ice baths for which the indicated temperature difference over periods of a few hours is less than $0.0001^{\circ} \mathrm{C}$ may be inferred from a statement of Scatchard, Jones, and Prentiss. ${ }^{2}$ This, however, gives no comparison between ice baths prepared from different materials at different times. Some information on this point, however, has just been published by White. ${ }^{3} \mathrm{He}$ used a special design of ice bath, and compared the temperature of one bath with that of another that had been prepared several days previously. The temperatures obtained were usually different, but this difference could be made as small as $0.0001^{\circ} \mathrm{C}$ by renewing the water in the baths.

\section{TRIPLE-POINT MEASUREMENTS}

While the preceding results seemed to show that the ice-bath temperatures repeat to a high degree of accuracy, it was desired to determine this temperature by comparing it with the triple point of water. For this purpose a triple-point container was constructed which was very similar to that built by Michels and Coeterier. ${ }^{4} \mathrm{~A}$ cross section of this container is shown in figure 1. The outer wall of the container is of pyrex glass $6 \mathrm{~cm}$ in diameter and about $25 \mathrm{~cm}$ in length. Into the top of this is sealed a long $1-\mathrm{cm}$ tube with an enlargement at the lower end. This tube is also of pyrex glass. Two heavy-walled tubes are sealed into the sides of the container near the top. These serve both as filling tubes and as supports for the container. The observations made with this container indicate that it would have been more satisfactory if the portion forming the well at $\mathrm{O}$ had been of the same diameter as the tube above it.

\footnotetext{
2 Jour. Am. Chem. Soc. vol. 54, p. 2688, 1932.

3 Walter P. White, Jour. Am. Chem. Soc. vol. 56, p. 20, 1934.

${ }^{4}$ Michels and Coeterier, Proc. K. Ak v. Wetensch. Amsterdam, vol. 30, p. 1017, 1927.
} 
The space $W$ between the two tubes was filled about three fourths full with pure water, the air above the surface of the water removed, and the container sealed. The well $O$ was then partly filled with mercury. The water in the space $W$ is partly frozen by immersing the container in a mixture of ice and salt. As the water will undercool, it is necessary to shake the container to start freezing. After the freezing has started, the container is removed from the ice and salt mixture and surrounded with cracked ice.

Since the melting temperature of the cracked ice is about $0.01^{\circ} \mathrm{C}$ lower than that of the water in $W$, the freezing of $W$ will now continue at a very slow rate. This leaves the space in $O$ almost completely surrounded with ice and water at the triple point. The space above the tube connecting to $O$ is at the ordinary ice point as the container is completely covered with the cracked ice. By this means the temperature in $O$ is kept. close to the temperature of the triple point of water for hours at a time. While this temperature varies slightly with the depth below the water surface, the variation is negligible as it amounts to only a few hundred thousandths of a degree centigrade.

After being soaked in distilled water for a month the triple-point container was filled in May 1931, evacuated and sealed, and some preliminary determinations were made of the difference in temperature between the triple point and the ice point. The first measurements were made with a special platinum resistance thermometer constructed by C. H. Meyers ${ }^{5}$ of this Bureau, used with a Mueller ${ }^{6}$ thermometer bridge. Two determinations of the difference between the temperature of an ice bath and the triple point each gave $0.0100 \mathrm{C} \pm 0.0005^{\circ} \mathrm{C}$.

In the spring of 1933, since some of the puremetal standards had remained very constant in resistance, it was decided to measure the temperature of the ice baths to a greater degree of accuracy. The same triple-point container was

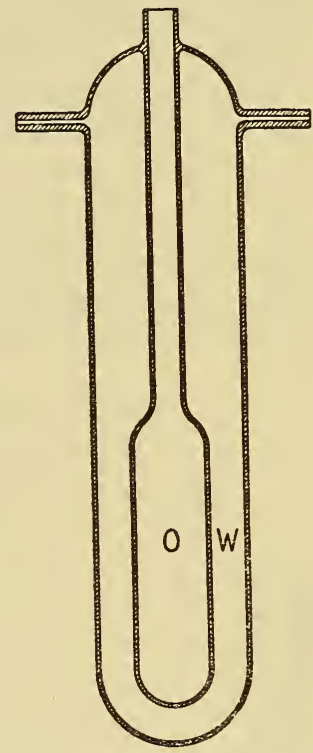

Figure 1.-Container for triple-point bath. used, and measurements of the temperature differences were made with the special thermocouple potentiometer designed and built at this Bureau by Brooks and Spinks. ${ }^{7}$ This potentiometer was designed to eliminate stray thermal emf's, and any error from this source was undoubtedly less than $0.0001^{\circ} \mathrm{C}$. A 50-junction copper-constantan couple was used which had a resistance of about $600 \mathrm{ohms}$, and the balance was indicated by a specially built galvanometer having an all-copper circuit. This galvanometer was adjusted to be properly damped when connected to the $600-\mathrm{ohm}$ couple, and gave a defiection of about 0.5 $\mathrm{mm}$ for an emf of 0.2 microvolt. That is, the temperature difference between the two ends of the couple could be read to $0.0001^{\circ} \mathrm{C}$ by adjusting the galvanometer balance to $0.5 \mathrm{~mm}$, which was readily done. The wires of the couple passed through a glass tube from the ice bath to the triple-point bath. This glass tube was packed in crushed ice, so 
that only the two copper lead wires passed through the temperature gradient between the ice baths and the room.

In measuring the temperature difference between the ice baths and the triple-point bath, it was found that a smaller difference was obtained if the couples were packed in ice and cooled before being inserted in the baths. This suggested that insufficient time had been allowed in the preliminary measurements for equilibrium conditions to be established. By waiting 24 hours the temperature difference obtained was the same whether the couples were pre-cooled or inserted while still at room temperature.

Before it was found necessary to wait 24 hours to make measurements, a series of eight measurements was made in March 1933. In this series four ice baths were used with two separate freezings of the triple-point bath. However, only the measurements which were made at least 24 hours after the couples were inserted in the baths are recorded in the table below.

After it was decided that it was necessary to wait 24 hours to make the measurements, the triple-point container was refilled and a series of 13 measurements was made extending from April 21, 1933 to May 26, 1933. For this series of measurements five separate ice baths were used, and the triple-point bath was melted and refrozen each time the ice bath was changed. The data obtained are given in the accompanying table, $\Delta t$ denoting the difference in temperature between the ice bath and the triple point, in degrees centigrade.

TABLE 1.-Comparison of ice bath and triple-point temperatures

\begin{tabular}{|c|c|c|c|c|c|}
\hline Date 1933 & $\begin{array}{l}\text { Ice bath } \\
\text { number }\end{array}$ & $\Delta t$ in ${ }^{\circ} C$ & Date 1933 & $\begin{array}{l}\text { Ice bath } \\
\text { number }\end{array}$ & $\Delta t$ in ${ }^{\circ} C$ \\
\hline \multirow[t]{2}{*}{$\begin{array}{l}\text { Mar. } 3 \\
\text { Mar. } 7 \\
\text { Mar. } 9 \\
\text { Mar. } 11 \\
\text { Mar. } 13 \\
\text { Mar. } 14 \\
\text { Mar. } 151 \\
\text { Apr. } 21 \\
\text { Apr. } 25 \\
\text { Apr. } 26 \\
\text { A pr. } 28\end{array}$} & \multirow[t]{2}{*}{$\begin{array}{r}1 \\
2 \\
3 \\
4 \\
4 \\
4 \\
4 \\
1 \\
2 \\
2 \\
2\end{array}$} & \multirow[t]{2}{*}{$\begin{array}{r}0.0097 \\
.0097 \\
.0097 \\
.0099 \\
.0098 \\
.0096 \\
.0097 \\
.0097 \\
.0098 \\
.0096 \\
.0097\end{array}$} & \multirow[t]{2}{*}{$\begin{array}{l}\text { Apr. } 29 \\
\text { May } 1 \\
\text { May } 2 \\
\text { May } 46 \\
\text { May } 16 \\
\text { May } 18 \\
\text { May } 24 \\
\text { May } 26 \\
\quad \text { A verage }\end{array}$} & $\begin{array}{l}2 \\
3 \\
3 \\
3 \\
4 \\
4 \\
4 \\
5 \\
5\end{array}$ & $\begin{array}{r}0.0097 \\
.0098 \\
.0097 \\
.0098 \\
.0096 \\
.0097 \\
.0097 \\
.0098 \\
.0098\end{array}$ \\
\hline & & & & & .0097 \\
\hline
\end{tabular}

${ }^{1}$ After this measurement the triple-point container was emptied and refilled.

The average barometric pressure during these determinations of $\Delta t$ was close to $75 \mathrm{~cm}$ of mercury. The spread in values obtained for $\Delta t$ was about what would result from changes in barometric pressure, although no correlation between the pressure and temperature was found. The average value of $0.0097^{\circ} \mathrm{C}$ checks very well with the results reported by other observers, if we assume that the ice baths are always saturated with air. Foote and Leopold ${ }^{8}$ state that air saturated ice melts at a temperature $0.0023^{\circ} \mathrm{C}$ below that of air-free ice, while Moser $^{9}$ found that the temperature of the triple point is $0.0074^{\circ} \mathrm{C}$ above that of melting air-free ice at standard pressure. A combination of their results shows that when the pressure is $76 \mathrm{~cm}$ of mercury air-saturated ice melts at a temperature which is $0.0097^{\circ} \mathrm{C}$ below the triple point.

8 Foote \& Leopold, Amer. Jour. Sci., vol. 11, p. 43, 1926.

- Moser, Annalen der Physik, vol. 393, p. 341, 1929. 


\section{SUMMARY}

In the preceding sections 3 groups of measurement are described in which a total of 34 ice baths was used. In the first two groups of measurements there is an uncertainty due to the electrical measurements amounting to possibly $0.0003^{\circ} \mathrm{C}$. In the case of the triplepoint measurements this uncertainty is believed to be not over $0.0001^{\circ} \mathrm{C}$. If these uncertainties of measurement are borne in mind it is seen that the range of variations in ice-bath temperatures is about what would be expected from the usual changes in barometric pressure. It is entirely possible that, if corrections are applied for barometric pressure, the ice point is reproducible to $0.0001^{\circ} \mathrm{C}$.

In order to obtain this accuracy it is, of course, necessary to use reasonable precautions in preparing the ice baths. Only clear parts of ice should be used; they should be rinsed with distilled water before shaving, and should be at all times handled with clean apparatus. It is probably necessary to use the ice baths in rooms where there is no open flame or other source of contaminating gases.

Washington, January 17, 1934. 